Forschungszentrum Karlsruhe

Technik und Umwelt

Wissenschaftliche Berichte

FZKA 6349

IAE-6150/3

\title{
Evaluation of Limits for Effective Flame Acceleration in Hydrogen Mixtures
}

S. B. Dorofeev, M. S. Kuznetsov,

V. I. Alekseev, A. A. Efimenko, W. Breitung

Institut für Kern- und Energietechnik

Projekt Nukleare Sicherheitsforschung 


\section{Forschungszentrum Karlsruhe}

Technik und Umwelt

Wissenschaftliche Berichte

FZKA 6349

IAE-6150/3

Evaluation of Limits for Effective Flame Acceleration in Hydrogen Mixtures

S.B. Dorofeev*, M.S. Kuznetsov*, V.I. Alekseev*, A.A. Efimenko* and $W$. Breitung

Institut für Kern- und Energietechnik

Projekt Nukleare Sicherheitsforschung

"Russian Research Centre "Kurchatov Institute" Moscow, Russia 


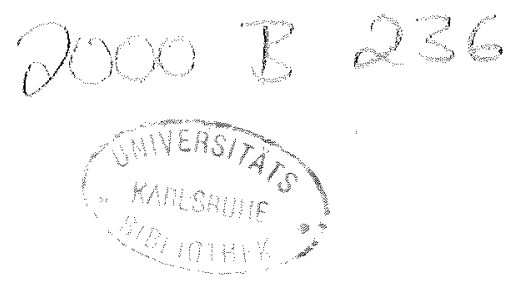

Als Manuskript gedruekt

Für diesen Bericht behalten wir uns alle Rechte vor

Forschungszentrum Karlsruhe GmbH

Postfach 3640, 76021 Karlsruhe

Mitglied der Hermann von Helmholtz-Gemeinschaft Deutscher Forschungszentren (HGF)

ISSN 0947-8620 


\section{ABSTRACT \\ Evaluation of Limits for Effective Flame Acceleration in Hydrogen Mixtures}

Results of experimental data analysis on turbulent flame propagation in obstructed channels is presented. The data cover a wide range of mixtures: $\mathrm{H}_{2} /$ air and $\mathrm{H}_{2} /$ air/steam mixtures (from lean to rich) at normal and elevated initial temperatures (from 298 to $650 \mathrm{~K}$ ) and pressures (from 1 to 3 bars); and stoichiometric $\mathrm{H}_{2} / \mathrm{O}_{2}$ mixtures diluted with $\mathrm{N}_{2}, \mathrm{Ar}, \mathrm{He}$, and $\mathrm{CO}_{2}$ at normal initial conditions. The data set chosen covers, also, a wide range of scales exceeding two orders of magnitude. It is shown that basic flame parameters, such as mixture expansion ratio $\sigma$, Zeldovich number $\beta$, and Lewis number $L e$, can be used to estimate a priori a potential for effective flame acceleration for a given mixture. The critical conditions for effective flame acceleration are suggested in the form $\sigma>\sigma^{*}(L e, \beta)$ on the basis of experimental correlations. Critical $\sigma^{*}$-values are found to be in the range from 3.5 to 4.0 , for stable flames $(\beta(L e-1)>-2)$. For unstable flames ( $\beta$ (Le $1)<-2$ ), $\sigma^{*}$ is given by a function of Zeldovich number $\beta$. The requirement of large enough mixture expansion ratio $\sigma>\sigma^{*}(L e, \beta)$ can be used in practical applications as the necessary condition or criterion for possible development of fast combustion regimes. On this basis, limits for effective flame acceleration can be defined for hydrogen combustibles. Uncertainties in determination of critical $\sigma^{*}$-values, which should be taken into account in practical applications, are discussed. 


\section{ZUSAMMENFASSUNG \\ Bestimmung der Bedingungen für Flammenbeschleunigung \\ in wasserstoffhaltigen Brenngasen}

Der Bericht beschreibt die Analyse von Versuchen zur turbulenten Flammenausbreitung in teilversperrten Rohren und Kanälen. Die ausgewerteten Daten decken ein weites Feld von Mischungen ab

- $\quad \mathrm{H}_{2} /$ Luft und $\mathrm{H}_{2} /$ Luft/Dampf, magere und reiche Gemische, Temperaturen von 298 bis $650 \mathrm{~K}$, Drücke von 1-3 bar,

- stöchiometrische $\mathrm{H}_{2} / \mathrm{O}_{2}-$ Mischungen mit verschiedenen inerten Zusätzen ( $\mathrm{He}, \mathrm{Ar}, \mathrm{Ne}, \mathrm{CO}_{2}$ ) bei Umgebungsbedingungen.

Die Daten umfassen außerdem einen weiten Bereich an geometrischen Skalen, die sich um mehr als zwei Größenordnungen unterscheiden.

Es wird gezeigt, daß grundlegende Flammenparameter wie das Expansionsverhältnis $\sigma$, die Zeldovich-Zahl $\beta$, und die Lewis-Zahl Le benutzt werden können, um das Potential für Flammenbeschleunigung in einer gegebenen Mischung vorherzusagen. Als kritische Bedingung für Flammenbeschleunigung wird eine Korrelation der Form

$$
\sigma>\sigma^{*}(\text { Le, } \beta)
$$

aus den Daten abgeleitet, d.h. nur wenn das Expansionsverhältnis der untersuchten Wasserstoffmischung größer als ein bestimmter kritischer Wert $\sigma^{*}$ ist (der von den Kennzahlen Le und $\beta$ abhängt), kann Flammenbeschleunigung auftreten. Das kritische Expansionsverhältnis $\sigma^{*}$ liegt bei stabilen Flammen, die durch $\beta$ (Le-1) >-2 gekennzeichnet sind, zwischen 3.5 und 4.0. Für instabile Flammen $\left(\beta(\right.$ Le-1) $<-2)$ ist $\sigma^{*}$ eine Funktion der Zeldovich-Zahl $\beta$, oder indirekt eine Funktion der Ausgangstemperatur $\mathrm{T}_{u}$.

Die Bedingung eines hinreichend großen Expansionsverhältnisses $\sigma>\sigma^{*}$ (Le, $\beta$ ) kann in praktischen Anwendungen als ein notwendiges Kriterium für das mögliche Auftreten von schnellen Verbrennungsformen benutzt werden. Auf dieser Basis lassen sich konservative Grenzen für Flammenbeschleunigung in wasserstoffhaltigen Brenngasen angeben. Die derzeit noch vorhandenen Unsicherheitsquellen in den kritischen $\sigma^{*}$-Werten werden dargestellt. 


\section{CONTENTS}

1. Introduction 5

2. Experimental data 6

3. Mixture properties $\quad 7$

4. Data analysis 8

5. Practical applications and uncertainties 10

$\begin{array}{ll}\text { Summary and conclusions } & 12\end{array}$

References 13 


\section{NOMENCLATURE}

\section{Latin}

$A$ - elementary area of the flame surface;

$B R=1-d^{2} / D^{2}-$ blockage ratio;

$c_{s r}$ - sound speed in reactants;

$c_{s p}$ - sound speed in combustion products;

$D$ - tube diameter;

$d$ - size of orifice;

$E_{a}$ - effective activation energy;

$h$ - height of obstacles;

$L$ - characteristic geometrical size (e.g., obstacle spacing);

$L_{T}$ - integral length scale of turbulence;

Le - Lewis number;

$L e_{f}$ - Lewis number defined by fuel diffusion coefficient in stoichiometric mixture;

$L e_{o}$ - Lewis number defined by oxidizer diffusion coefficient in stoichiometric mixture;

$M a_{b}$ - Markstein number defined relative to burned mixture;

$n_{f}$-reaction order for fuel;

$n_{o}$ - reaction order for oxidizer;

$R$ - gas constant;

$S_{L}$ - laminar burning velocity relative to unburned mixture;

$T_{b}$ - maximum flame temperature;

$T_{u}$ - initial mixture temperature;

$U_{n}$ - normal burning velocity of stretched flames relative to burned mixture;

$U_{L}$ - laminar burning velocity relative to burned mixture;

\section{Greek}

$\beta=E_{a}\left(T_{b}-T_{w}\right) /\left(R T_{b}^{2}\right)$ - Zeldovich number;

$\gamma_{r}$ - specific heat ratio in reactants;

$\delta=\chi\left(T_{b}\right) /\left(S_{L} \sigma\right)$ - laminar flame thickness;

$\sigma$ - ratio of densities of reactants and products (expansion ratio);

$\chi$ - temperature diffusivity. 


\section{INTRODUCTION}

Processes of turbulent flame propagation in obstructed tubes (channels) with different blockage ratios were studied in our previous works [1,2]. Explosion channel 80x80 mm and cylindrical tubes $174,350,520 \mathrm{~mm}$ i. d. were used in the tests. Blockage ratios were $0.09,0.1,0.3,0.6$, and 0.9 . Explosion processes were studied in hydrogen-air mixtures (lean and rich, with variable $\mathrm{H}_{2}$ concentration) and in stoichiometric hydrogen-oxygen mixtures diluted with $\mathrm{N}_{2}, \mathrm{Ar}, \mathrm{He}$, and $\mathrm{CO}_{2}$ (with variable concentrations of diluent gases). All tests were made at normal initial temperature and pressure.

A set of dimensionless parameters was chosen in $[1,2]$ to analyze the results. These parameters can influence the flame-flow-flame feedback in obstructed areas. They are defined by intrinsic length, time and velocity scales of combustion processes and by mixture properties:

$$
L / \delta, \sigma, S_{L} / c_{s r}, S_{L} / c_{s p}, \gamma_{r}, \text { Le, and } \beta,
$$

where $L_{T}$ - integral length scale of turbulence, $\delta$ - laminar flame thickness, $\sigma$ - ratio of densities of reactants and products (expansion ratio), $S_{L}$ - laminar burning velocity, $c_{s r}$ and $c_{s p}$ - sound speeds in reactants and products, $\gamma_{r}$ - specific heat ratio in reactants, $L e$ - Lewis number, $\beta=E_{a}\left(T_{b}-T_{u}\right) /\left(R T_{b}{ }^{2}\right)$ - Zeldovich number, $E_{a}$ - effective activation energy, $T_{u}$ initial, and $T_{b}$ - maximum flame temperature. Different mixtures were chosen in order to provide (i) a wide range of the scaling parameters, and (ii) combinations with similar values of the parameters at different scales.

Flame propagation in explosion channels was found to result in one of the following four characteristic combustion regimes. Unstable/quench - relatively slow flame propagation with variable speed resulted in global extinguishing of flame at some distance along the tube. Unstable/slow - relatively slow flame propagation with variable speed (the same as previous regime, but in the cases when flame reached the end of the tube). Choked flames - quasi-steady flame propagation with a speed close to isobaric sound speed in combustion products. Quasi-detonation - quasi-steady propagation of explosion wave with a speed somewhat below the CJ detonation velocity due to momentum losses in obstacle field.

Some differences in characteristic features of the flame propagation in obstructed areas with different blockage ratios were found in the tests [2]. Despite these differences, the following general observations were made, which are important to characterize a potential for flame acceleration under given initial conditions.

It was shown that scale plays an important role influencing rate of flame acceleration and propagation speed of slow flames; both tend to increase with scale in most cases. Possibility of development of fast combustion regimes was also found to depend on scale. However, at sufficiently large scale $\left(L_{T} / \delta>100\right)$, such a possibility was found to depend only on the mixture composition.

The difference between slow regimes (unstable/quench and unstable/slow) and fast regimes (choked flames and detonations) was found to be the most pronounced for all mixtures, scales and geometrical configurations tested. This difference gives a welldefined measure of effectiveness of flame acceleration. Mixture properties were shown to provide a potential for effective flame acceleration. This potential can be realized, if geometry of confinement and scale provide conditions favorable for flame acceleration. 
It was shown that for mixtures and initial thermodynamic conditions used in $[1,2]$ (hydrogen mixtures at normal initial temperature and pressure), the potential for effective flame acceleration is defined mainly by the value of mixture expansion ratio $\sigma$. Development of fast combustion regimes was found to be only possible in mixtures with $\sigma>\sigma^{*}=3.75 \pm 0.25$.

It was suggested, also, that initial thermodynamic conditions are expected to influence the critical value of $\sigma^{*}$ mainly through changes of Lewis and Zeldovich numbers $L e$, and $\beta$. Results of the tests [1,2] alone, were not sufficient to make a more general characterization of conditions for effective flame acceleration.

At the same time there are other sources of experimental data available on propagation of turbulent flames in obstructed tubes. Some of them are significantly different in the initial conditions from [1,2] (elevated initial temperature and pressure); and can provide important additional information. The objective of the present work is to analyze behavior of turbulent flames in hydrogen mixtures using the widest possible set of available experimental data.

\section{EXPERIMENTAL DATA}

A considerably large amount of experimental data on turbulent flame acceleration in hydrogen mixtures are available besides data $[1,2]$. Most of the tests have been obtained in connection with analyses of hydrogen safety in severe nuclear reactor accidents. Experimental conditions were chosen to be representative for nuclear safety. In this section we consider these data. Main experimental conditions of these tests are presented in Table 1.

Experimental results obtained at Brookhaven National Laboratory (BNL) concern combustion phenomenon in hydrogen-air and hydrogen-air-steam mixtures differed in hydrogen and steam concentration [3]. The High-Temperature Combustion Facility (HTCF) is 21.3-meters long and has an internal diameter of $27.3 \mathrm{~cm}$. Periodic orifice plates were installed down the length of the entire detonation tube. The orifice plates have an outer diameter of $27.3 \mathrm{~cm}$, an inner diameter of $20.6 \mathrm{~cm}$, and a spacing of one tube diameter.

Experiments at SANDIA National Laboratories were conducted with hydrogen-air-steam and hydrogen-air mixtures in the Heated Detonation Tube (HDT), $43 \mathrm{~cm}$ in diameter and $12 \mathrm{~m}$ long [4]. Annular obstacles were used with $30 \%$ blockage ratio, and alternate rings and disks with $60 \%$ blockage ratio. The initial conditions were $383 \mathrm{~K}$ and one or three atmospheres pressure.

RUT facility tests were performed at RRC KI with hydrogen-air mixtures with and without steam dilution in a complex geometry $[5,6]$. The first part of the facility was a channel of $2.5 \times 2.3-\mathrm{m}$ cross-section and $34.6 \mathrm{~m}$ long; the second part was a canyon of $6 \times 2.5-\mathrm{m}$ cross-section and $10.5 \mathrm{~m}$ long, and the third one was a channel of $2.5 \times 2.3-\mathrm{m}$ cross-section and $20 \mathrm{~m}$ long. Twelve concrete obstacles were placed along the first channel with a spacing of $2.5 \mathrm{~m}$ (blockage ratios were $30 \%$ and $60 \%$ ). Initial temperature in the tests with steam was close to $375 \mathrm{~K}$. Initial pressure in all the tests was atmospheric.

FLAME facility data (SANDIA) were obtained while studying the flame acceleration and DDT in hydrogen-air mixtures [7]. FLAME is a large (30.5-m long) rectangular channel, 
its interior width is $1.83 \mathrm{~m}$, height $-2.44 \mathrm{~m}$. Blockage ratio was 0 or $33 \%$ in the tests. Initial conditions were normal in these tests.

Experimental results are described in details in the references given herein. This made it possible, in most cases, to classify the resulting regime of flame propagation in the same way, as it was done in $[1,2]$. All the regimes were attributed, thus, to one of the following categories: unstable/quench, unstable/slow, choked flames, and quasi-detonations. We should note that different classifications were used in some of the original studies, making use of a critical level of maximum pressure rise, e. g., to classify a flame acceleration limit, as it was done in [4].

The main attention in the present analysis is focused on the border between slow (unstable/quench and unstable/slow) and fast (choked flames and detonations) regimes. Critical conditions for deflagration to detonation transition (DDT) are not discussed in the present work. An analysis of DDT conditions, which is based on the similar data set, can be found in [8].

\section{MIXTURE PROPERTIES}

Experimental data on $S_{L}$ were collected from [9-20]. For each type of mixture an appropriate analytical function was chosen to describe dependencies of $S_{L}$ on hydrogen concentration (or diluent concentration). Least squares fits of these functions with experimental data permitted to calculate the laminar burning velocities for most of the mixture compositions used in the tests. It appeared, however, that experimental data on $S_{L}$ are not available for the entire range of mixtures tested. The lack of data was felt for lean hydrogen mixtures near the limit of propagation at elevated temperatures; for some of rich mixtures at elevated temperatures and pressures; and for some of $\mathrm{H}_{2} / \mathrm{O}_{2} / \mathrm{CO}_{2}$ and $\mathrm{H}_{2} /$ air/ $/ \mathrm{CO}_{2}$.

The following approach was used to estimate $S_{L}$-values in the cases direct experimental data were missing. It was assumed that $\ln \left(S_{L}\right)$ is proportional to $E_{o} /\left(2 R T_{b}\right)$, and the effective activation energy $E_{a}$ is constant for a given type of mixture.

$$
\ln \left(S_{L}\right) \propto E_{d} /\left(2 R T_{b}\right)
$$

A value of $S_{L}$ was taken for the nearest available mixture composition (the same mixture type) and an extrapolation was made to desired composition according to $T_{b}$ using Eq. 2 with constant $E_{a}$. Determination of $E_{a}$ is described below. Such estimates of $S_{L}$-values were treated with care, and no conclusions were made on the basis of these values.

Values of the thermal thickness of the laminar flame $\delta$ were calculated from the laminar burning velocities and temperature diffusivity:

$$
\delta=\chi\left(T_{b}\right) /\left(\sigma S_{L}\right)
$$

Values of $\chi\left(T_{b}\right)$ were determined using Ref. [21,22]. Values of $T_{b}, \sigma, \gamma, c_{s r}$, and $c_{s p}$ were calculated using STANJAN code [23].

The following definitions of integral length scale of turbulence $L_{T}$ were used for determination of the scale ratio $L_{T} / \delta[2]$ :

$$
\begin{array}{ll}
L_{T}=h=D \cdot\left(1-(1-B R)^{1 / 2}\right) / 2, & \text { for } B R=0.1 ; \\
L_{T}=D=L, & \text { for } 0.3 \leq B R \leq 0.6 ;
\end{array}
$$




$$
L_{T}=d=D \cdot(1-B R)^{1 / 2}, \quad \text { for } B R=0.9 .
$$

These definitions imply that integral length scale of turbulence $L_{T}$ is defined by geometry. It is given approximately by the height of obstacles $h$, for $B R=0.1$; by the tube diameter $D$ or obstacle spacing $L$, for $0.3 \leq B R \leq 0.6$; and by the size of the orifice $d$, for $B R=0.9$.

Determination of parameters $\beta$ and $L e$ is not always simple for real mixtures. In the present study, Lewis numbers for $\mathrm{H}_{2}$-lean and $\mathrm{H}_{2}$-rich mixtures were defined by the diffusion coefficient of the limiting component and temperature diffusivity of the mixture. For stoichiometric mixtures, Le was determined as follows [24]:

$$
L e=\left(n_{o} L e_{o}+n_{f} L e_{d}\right) /\left(n_{o}+n_{f}\right),
$$

where $L e_{o} L e_{f}$ are Lewis numbers for oxidant and fuel; $n_{o}$ and $n_{f}$ are orders of reaction. Values of $n_{o}=2$, and $n_{f}=1$ were assumed.

Effective activation energies $E_{a}$ were determined from dependencies of $S_{L}\left(T_{b}\right)$. For that, $\ln \left(S_{L}\right)$ was plotted versus $1 / T_{b}$ (see Fig. 1). The slope, evaluated with the least squares method, gave the value of $E_{d} / R$. For all types of mixtures, except $\mathrm{H}_{2}$-rich ones, the experimental data show rather good linear behavior in $\ln \left(S_{L}\right)$ and $1 / T_{b}$ variables. For rich mixtures, $E_{a}$-value was evaluated for the composition range which is close to the border between fast and slow combustion regimes (see Fig. 1).

The following values of effective activation energies were determined:

$E_{d} / R=9800 \mathrm{~K}$, for lean $\mathrm{H}_{2} /$ air;

$E_{d} / R=17700 \mathrm{~K}$, for rich $\mathrm{H}_{2} /$ air;

$E_{d} / R=10400 \mathrm{~K}$, for stoichiometric $\mathrm{H}_{2} / \mathrm{O}_{2} / \mathrm{N}_{2} ;$

$E_{d} / R=11200 \mathrm{~K}$, for stoichiometric $\mathrm{H}_{2} / \mathrm{O}_{2} / \mathrm{He}$;

$E_{d} / R=11600$, for stoichiometric $\mathrm{H}_{2} / \mathrm{O}_{2} / \mathrm{Ar}$.

It was assumed that additional dilution of the rich, lean, and stoichiometric mixtures with $\mathrm{CO}_{2}$ and $\mathrm{H}_{2} \mathrm{O}$ does not change the effective activation energies given by values for undiluted hydrogen-air and $\mathrm{H}_{2} / \mathrm{O}_{2} / \mathrm{N}_{2}$ mixtures. Corresponding values of Zeldovich number were determined from $E_{a}$ and $T_{b}$.

\section{DATA ANALYSIS}

The effect of mixture properties on the resulting regime of flame propagation in obstructed channels (tubes) is analyzed in this section. As it was found out in $[1,2]$, mixture expansion ratio $\sigma$ was the most important parameter, defining a potential for flame acceleration in hydrogen mixtures at normal initial temperature and pressure. Here, the whole set of experimental data presented in Table 1 is examined to correlate the resulting regime of flame propagation with experimental conditions.

Data with large enough scale ratio for effective flame acceleration $L_{T} / \delta>100$ were selected according to [2]. For the given set of data, it was not a strong limitation. Only some data with $B R=0.1$ at relatively small scale (channel $80 \times 80 \mathrm{~mm}$ and tube $174 \mathrm{~mm}$ i. d.) appeared to be excluded from the analysis. Results are presented in Figs $2-7$. Data points are marked with labels given in Table 1. Black points correspond to fast combustion regimes and light gray points to slow combustion regimes. 
The plot of $\sigma$-values versus initial temperature is shown in Fig. 2. It is seen that the border between fast and slow flames in terms of $\sigma$ goes down with initial temperature. In fact, such a behavior should be expected. The mixtures are characterized by the intrinsic temperature scale - parameter $E_{d} / R$. In dimensionless form the rigorous parameter is Zeldovich number $\beta=E_{a}\left(T_{b}-T_{u}\right) /\left(R T_{b}{ }^{2}\right)$, which changes with variations of initial temperature.

Qualitatively, the influence of the initial temperature on the effectiveness of flame acceleration is connected with the increase of the effect of local turbulent mixing on suppression of combustion processes at high $\beta$-values. The increase of the initial temperature results in the decrease of Zeldovich number. This should result, generally, in some decrease of ability of turbulent mixing to quench locally the combustion process. Such a general effect, however, is expected to be influenced by a local behavior of a flame element which is stretched and curved by turbulent motions.

Zeldovich number is known to play an important role in stability of stretched flames in combination with Lewis number (see e. g., [25]). Normal burning velocity of stretched flames $U_{n}$ relative to burned mixture may be expressed by

$$
U_{n} / U_{L}-1=-M a_{b} \delta / U_{L} \cdot(1 / A \cdot d A / d t),
$$

where $U_{L}$ - laminar burning velocity relative to burned mixture, $A$ - elementary area of the flame surface, $M a_{b}$ - Markstein number defined relative to burned mixture. We chose here the reference system connected with burned gases, which is close to the system with fixed observer in our case of flame propagation from the closed end of channels.

The value $(1 / A \cdot d A / d t)$ in Eq. 6 represents the flame stretch, which in highly turbulent flow is defined, mainly, by the turbulence level. The value of Markstein number $M a_{b}$ determines the effect of stretch on variations of local burning velocities. For two reactant mixture with a single step reaction the $M a_{b}$ is estimated as [25]:

$$
M a_{b}=(\sigma /(\sigma-1)) \cdot\left(\ln \sigma+(\beta(L e-1) / 2 /(\sigma-1)) \cdot \int_{0}^{\sigma-1}(\ln (1+x) / x) d x\right)
$$

where $x$ is dummy variable of integration.

The combination $\beta(L e-1)$ defines the value and even the sign of Markstein number. At large negative values of $\beta(L e-1), M a_{b}<0$, and stretch results in local increase of the burning velocity. With $M a_{b}>0$, stretch tends to decrease the burning velocity and can result in the flame quench.

The combination $\beta(L e-1)$ is also the defining parameter for the well-known thermaldiffusion flame instability. The stability boundary corresponds to $\beta(L e-1)=-2$. Flames are stable with $\beta(L e-1)>-2$ and unstable with $\beta(L e-1)<-2$. These speculations show that $M a_{b}$ and $\beta(L e-1)$ are expected to be important in correlations of experimental data.

Figure 3 shows combustion regimes in $\sigma$ and $\beta(L e-1)$ variables. The value $\beta(L e-1)=-2$ indeed appears as a threshold value. With $\beta(L e-1)<-2$ the borderline between slow and fast combustion regimes changes with $\beta($ Le-1) in the range $\sigma=2-3.75$. These changes are mainly due to the variations of $\beta$ value. With $\beta(L e-1)>-2$, which corresponds to stable flames, an abrupt change of limiting values of $\sigma$ is observed. Values of $\sigma$ ranges from 3.5 to 4.0 for $\beta(L e-1)>-2$. Similar picture is seen with $\sigma$ and $M a_{b}$ variables presented in Fig. 4. Threshold value here corresponds to $M a_{b}=0$. 
The data plots in Figs. 3 and 4 show that microscopic flame properties reveal themselves at a macroscopic level. Indeed, the final regime of flame propagation in obstructed tubes (shown by the type of data points in Figs. 3 and 4) is a result of the whole history of flame acceleration from an ignition point. The regime is a global characteristic of the flame behavior. Locally, different regimes of turbulent combustion can be found at different stages inside the channel. It is remarkable that the parameters $\sigma, \beta(L e-1)$, and $M a_{b}$, defining microscopic flame properties, prescribe the type of the flame behavior in a wide range of scales, mixtures, and geometrical configurations. This observation gives an important additional argument in favor of the conclusions $[1,2]$ that mixture properties define a priori a potential for flame acceleration, and that mixtures can be divided into "strong" and "weak".

Data of Figs. 3 and 4 suggest that correlations with other parameters should be made separately for mixtures with $\beta(L e-1)<-2$ and with $\beta(L e-1)>-2$. For stable flames with $\beta(L e-1)>-2$, these correlations are presented in Figs. 5 and 6 . Critical $\sigma$-values for effective flame acceleration do not depend significantly on scale ratio $L_{T} / \delta$ (Fig. 5) and on Zeldovich number $\beta$ (Fig. 6). Thus, for stable flames, the critical values of $\sigma$ (if defined by the range from 3.5 to 4 ) are not influenced by possible inaccuracy of determination of $\beta, \delta$, and $L_{T}$.

For unstable flames $(\beta(L e-1)<-2)$, critical $\sigma$-values can be considered to be a function of Zeldovich number $\beta$ (Fig. 7). No correlation is observed in $\left(\sigma-L_{T} / \delta\right)$ plot shown in Fig. 8. All changes of critical $\sigma$-values are described by corresponding variations of Zeldovich number. Since determination of $E_{a}$ and $\beta$ were not accurate for some of the hydrogen-airsteam mixtures, $\left(\sigma-T_{u}\right)$ plot is given in Fig. 9 for these type of mixtures. This plot gives the correlation of combustion regimes for unstable flames, which is not influenced by possible inaccuracy of $E_{a}$ determination.

\section{PRACTICAL APPLICATIONS AND UNCERTAINTIES}

Correlations for experimental data presented in the previous Section suggest the following critical values which define the potential for effective flame acceleration:

$$
\begin{aligned}
& \sigma>(3.5 \div 4), \text { for mixtures with } \beta(L e-1)>-2 \\
& \sigma>\dot{\sigma}^{*}(\beta), \quad \text { for mixtures with } \beta(L e-1)<-2,
\end{aligned}
$$

where $\sigma^{*}(\beta)$ - function is given by correlation in Fig. 7. These conditions are expressed in terms of mixture properties and give a possibility to divide mixtures into "strong" and "weak", depending on their ability to support effective flame acceleration under favorable geometrical conditions. Equations 8 and 9, thus, can be used in practical applications as the necessary conditions or criteria for development of fast combustion regimes. Since these critical conditions are described in terms of mixture properties only, one can define flame acceleration limits (similar to flammability limits) on the basis of Eqs. 8 and 9, as the critical mixture compositions for effective flame acceleration at given initial temperature and pressure.

There are some uncertainties connected with estimations of the potential for flame acceleration. First of all, it should be emphasized that criteria $(8,9)$ can be used only as necessary, but not sufficient conditions for effective flame acceleration. Other requirements should also be met in order the flame can accelerate to fast combustion regimes. The most important of them are the requirements of large enough scale (flame 
propagation distance) and favorable geometry (obstructions) for effective flame acceleration.

The critical values defined by Eqs. 8 and 9 were found from correlations of experimental data over the given range of hydrogen mixtures. Although variations of the basic mixture properties were rather wide over this range, applications of the same critical conditions to different types of mixtures (e. g., for hydrocarbons) require an experimental confirmation. The critical conditions $(8,9)$ should be only applied for the given range of hydrogen mixtures

Another type of uncertainties is connected with a spread of critical $\sigma$-values. For $\mathrm{H}_{2}$-rich mixtures, it is given by the range of $\sigma^{*}$ from 3.5 to 4.0 . It should be noted, also, that no experimental data are available for rich hydrogen-air-steam mixtures at $T_{u}>383 \mathrm{~K}$. Additional experiments are required to evaluate the limit (Eq. 8) for $\mathrm{H}_{2}$-rich mixtures at $T_{u}>383 \mathrm{~K}$.

A considerable spread in the limiting $\sigma$-values from 3.5 to 4.0 may be connected with possible influence of additional parameters on effectiveness of flame acceleration. In particular, the laminar flame Mach number $S_{L} / c_{s r}$ may play a role. An accurate estimation of possible influence of this parameter is difficult, since no reliable data on $S_{L}$ are available for some mixture compositions. In view of this, a definition of critical conditions in terms of $\sigma$ (even taking into account the spread of critical values) should be considered as more reliable, because $\sigma$-values are given just by thermodynamic mixture properties.

For lean mixtures, the scatter of limiting $\sigma$-values (Fig. 7) can be estimated as $\pm 4 \%$. This gives, e. g., the range of $\sigma^{*}$ from 2.7 to 2.9 for $\beta \approx 5.5\left(T_{u} \approx 400 \mathrm{~K}\right)$. If hydrogen-air-steam mixtures are considered without additional components or dilution (e. g., $\mathrm{CO}_{2}, \mathrm{~N}_{2}, \mathrm{CO}$, etc.), the unavoidable uncertainty connected with determination of $E_{a}$ (and, hence, $\beta$ ) can be eliminated by using limiting $\sigma^{*}\left(T_{u}\right)$-values from Fig. 9 instead of those from Fig. 7. In other cases, the critical condition in form of $\sigma^{*}(\beta)$ is preferable, and the uncertainty in $\beta$ value should be taken into account.

Third type of uncertainty is connected with the border between stable and unstable flames, which is defined by $\beta(L e-1)=-2$. The exact location of this border in terms of mixture composition under given initial conditions is difficult to define due to inevitable errors in determination of $L e$ and $\beta$. It is also unclear, how sharp is the difference in limiting conditions for mixtures which are close to this stability boundary. No experimental data are available for mixtures with $\beta($ Le-1) from -2.2 to -1.3 in Figs. 2-8. Additional analysis and, probably, experiments are necessary to clarify critical conditions for mixtures with equivalence ratio $\phi$ from 0.7 to 1.0 .

Limits of effective flame acceleration for hydrogen-air-steam mixtures at $\mathrm{T}=375 \mathrm{~K}$ and $\mathrm{p}=1 \mathrm{~atm}$ and corresponding uncertainties are shown as an example in Fig. 10. The uncertainties discussed above, still allow practical applications of the criterion for flame acceleration limits. These uncertainties should be taken into account by using conservative estimates, that is, by using the minimum $\sigma^{*}$-values for each set of initial conditions. Additional experiments and analysis can help in narrowing the range of uncertainties and reducing the level of conservatism in estimates of the mixture potential for effective flame acceleration. 


\section{SUMMARY AND CONCLUSIONS}

We have presented results of experimental data analysis on turbulent flame propagation in obstructed channels. The analysis was focused on determination of critical conditions for effective flame acceleration in hydrogen combustibles. The data covered a wide range of mixtures: $\mathrm{H}_{2}$ /air and $\mathrm{H}_{2}$ /air/steam mixtures (from lean to rich) at normal and elevated initial temperatures (from 293 to $650 \mathrm{~K}$ ) and pressures (from 1 to 3 bars); and stoichiometric $\mathrm{H}_{2} / \mathrm{O}_{2}$ mixtures diluted with $\mathrm{N}_{2}, \mathrm{Ar}, \mathrm{He}$, and $\mathrm{CO}_{2}$ at normal initial conditions. The data covered also a wide range of scales exceeding two orders of magnitude, $\left(L_{T} / \delta\right.$ from 100 to 30000$)$.

It was found that the basic flame parameters, such as mixture expansion ratio $\sigma$, Zeldovich and Lewis numbers, defining microscopic flame properties, are able to prescribe the type of the macroscopic flame behavior over a wide range of scales, mixtures, and geometrical configurations. It was shown that these parameters can be used to estimate a priori a potential for effective flame acceleration for a given mixture.

The critical conditions for effective flame acceleration were suggested in the form $\sigma>\sigma^{*}(L e, \beta)$, with critical values $\sigma^{*}$ given by experimental correlations. The critical values of expansion ratio $\sigma^{*}$ were found to be in the range from 3.5 to 4.0 , for stable flames with $\beta(L e-1)>-2$. For unstable flames with $\beta(L e-1)<-2, \sigma^{*}$ was essentially found to be a function of Zeldovich number $\beta$.

It was suggested that the requirement of the large enough mixture expansion ratio $\sigma>\sigma^{*}(L e, \beta)$ can be used in practical applications as the necessary condition or criterion for development of fast combustion regimes. On this basis, limits for effective flame acceleration can be defined for hydrogen combustibles, as the critical compositions at given initial temperature and pressure. It was shown, also, that there are some uncertainties in determination of the critical $\sigma^{*}$-values, which should be taken into account in practical applications. 


\section{REFERENCES}

1. S. B. Dorofeev, M. S. Kuznetsov, V. I. Alekseev, A. A. Efimenko, A. V. Bezmelnitsyn, Yu. G. Yankin, and W. Breitung. Effect of scale and mixture properties on behavior of turbulent flames in obstructed areas. Preprint IAE-6127/3, RRC "Kurchatov Institute" Report FZKA-6268, Forschungszentrum Karlsruhe, 1999

2. M. Kuznetsov, V. Alekseev, A. Bezmelnitsyn, W. Breitung, S. Dorofeev, I. Matsukov, A Veser, and Yu. Yankin. Effect of obstacle geometry on behavior of turbulent flames. Preprint IAE-6137/3, RRC "Kurchatov Institute", Report FZKA-6328, Forschungszentrum Karlsruhe, 1999

3. Ciccarelly G., J. Boccio. T. Ginsberg, C. Finfrock, L. Gerlach, H. Tagava, and A. Malliakos. The Effect of Initial Temperature on Flame Acceleration and Deflagrationto-Detonation Transition Phenomenon. NUREG/CR-6509, BNL-NUREG-52515, 1998.

4. Sherman M., M. Berman, and R. Beyer. Experimental Investigation of Pressure and Blockage Effects on Combustion Limits in $\mathrm{H}_{2}$-Air-Steam Mixtures. SAND 91-0252, 1993.

5. Dorofeev S. B., Sidorov V. P., Dvoinishnikov A. E., Breitung W. Combustion and Flame 104: 95 - 110 (1996)

6. Dorofeev S., V. Sidorov, A. Dvoinishnikov, A. Denkevits, A. Efimenko, and A. Lelyakin. Large Scale Hydrogen-Air-Steam DDT Experiments in the RUT Facility. Test Series 1996. Report RRC KI 80-05/16, 1997.

7. Sherman M., S. Tieszen, and W. Benedick. The Effect of Obstacles and Transverse Venting on Flame Acceleration and Transition to Detonation for Hydrogen-Air Mixtures at Large Scale. NUREG/CR-5275, SAND 85-1264, 1989.

8. S. B. Dorofeev, V. P. Sidorov, M. S. Kuznetsov, I. D. Matsukov, and V. I. Alekseev. Effect of scale on the onset of detonations. Proc. of $17^{\text {th }}$ International Colloquium on Dynamics of Explosions and Reactive Systems, paper No. 141 on CD, Heidelberg, Germany, 1999

9. Koroll G. W., S. R. Mulpuru. 21st Symp. (Int.) on Combustion/The Combustion Institute, 1986, pp. 1811-1919

10. Koroll G. W., R. K. Kumar, E. M. Bowles. Combustion and Flame 94: 330-340 (1993)

11. Gunther R., and G. Janish, Combustion and Flame 19: 49-53 (1972)

12. Liu D. D. S., and R. McFarlane, Combustion and Flame 49: 59-71 (1983)

13. Andrews G. E., and D. Bradley, Combustion and Flame 20: 77-89 (1973)

14. Berman M. Sandia Laboratories Report, SAND84-0689, 1984.

15. Karpov V. P., E. S. Severin, Influence of coefficient of molecular transport on turbulent combustion velocity, Fizika Goreniya i Vzryva, Vol. 16, No 1 (1980) - in Russian

16. Babkin V. C., A. V. V'yun, Fizika Goreniya i Vzryva, 7:3(1971) - in Russian

17. Coward H., and W. Payman, Chem. Rev., 21:359 (1937) 
18. Coward H., and G. Jones, J. Am. Chem. Soc., 49:386 (1927)

19. Kusharin A. Yu., O. M. Popov, and G. L. Agafonov. J. Chem. Phys., 14: 179-189 (1995)- in Russian.

20. Khitrin L. N. The Physics of Combustion and Explosion, Moscow State University Publishers, Moscow, 1957) - in Russian.

21. Reid R. C., J. M. Prausnitz, T. K. Sherwood. The properties of gases and liquids, $3^{\text {rd }}$ edition, McGraw-Hill Book Company, NY, London, Tokyo, 1976.

22. Vargaftic N. B. Thermo-physical properties of gases and liquids. (Handbook), Moscow, "Nauka" Publishers, 1972, 720 p.

23. Reynolds, W. C., The Element Potential Method for Chemical Equilibrium Analysis: Implementation in the Interactive Program STANJAN Version 3, Dept. of Mechanical Engineering, Stanford University, Palo Alto, California, January 1986.

24. Joulin G. and T. Mitani. Linear stability analysis of two-reactants flames. Combustion and Flame 40: 235-246 (1981)

25. P. Clavin. Prog. Energy Combust. Sci., 1985, v11, pp 1-59. 
Table 1.

Experimental data used in correlations.

\begin{tabular}{|c|c|c|c|c|c|c|}
\hline Data source & Label & $\begin{array}{c}\text { Blockage } \\
\text { ratio } \\
B R \\
\end{array}$ & $\begin{array}{c}\text { Tube or } \\
\text { channel size } \\
L, \mathrm{~mm}\end{array}$ & $\begin{array}{c}\text { Initial } \\
\text { temperature } \\
T, \mathrm{~K} \\
\end{array}$ & Mixture type & $\begin{array}{c}\text { Equivalence } \\
\text { ratio } \\
\phi\end{array}$ \\
\hline HTCF-BNL [3] & $\mathrm{b} 1$ & 0.43 & 273 & 300 & $\mathrm{H} 2 / \mathrm{air}$ & $<1$ \\
\hline HTCF-BNL [3] & $\mathrm{b} 2$ & 0.43 & 273 & 500 & H2/air & $<1$ \\
\hline HTCF-BNL [3] & 63 & 0.43 & 273 & 650 & H2/air & $<1$ \\
\hline HTCF-BNL [3] & b4 & 0.43 & 273 & 400 & $\mathrm{H} 2 /$ air/H2O & $<1$ \\
\hline HTCF-BNL [3] & b5 & 0.43 & 273 & 500 & $\mathrm{H} 2 /$ air/H2O & $<1$ \\
\hline HTCF-BNL [3] & $\mathrm{b} 6$ & 0.43 & 273 & 650 & $\mathrm{H} 2 / \mathrm{air} / \mathrm{H} 2 \mathrm{O}$ & $<1$ \\
\hline CHANNEL-RRCKI [2] & $\mathrm{cl}$ & 0.1 & 80 & 293 & H2/air & $<1 ;>1$ \\
\hline CHANNEL-RRCKI [2] & $\mathrm{c} 2$ & 0.3 & 80 & 293 & H2/air & $<1 ;>1$ \\
\hline CHANNEL-RRCKI [2] & $\mathrm{c3}$ & 0.6 & 80 & 293 & H2/air & $<1 ;>1$ \\
\hline CHANNEL-RRCKI [2] & $\mathrm{c4}$ & 0.9 & 80 & 293 & H2/air & $<1 ;>1$ \\
\hline CHANNEL-RRCKI [2] & $c 5$ & 0.6 & 80 & 293 & $\mathrm{H} 2 / \mathrm{O} 2 / \mathrm{He}$ & 1 \\
\hline CHANNEL-RRCKI [2] & $\mathrm{c6}$ & 0.6 & 80 & 293 & $\mathrm{H} 2 / \mathrm{O} 2 / \mathrm{Ar}$ & 1 \\
\hline DRIVER-RRCKI [2] & $\mathrm{d} 1$ & 0.09 & 174 & 293 & H2/air & $<1 ;>1$ \\
\hline DRIVER-RRCKI [2] & $\mathrm{d} 2$ & 0.3 & 174 & 293 & $\mathrm{H} 2 / \mathrm{air}$ & $<1 ;>1$ \\
\hline DRIVER-RRCKI [2] & $\mathrm{d} 3$ & 0.6 & 174 & 293 & H2/air & $<1 ;>1$ \\
\hline DRIVER-RRCKI [2] & $\mathrm{d} 4$ & 0.9 & 174 & 293 & H2/air & $<1 ;>1$ \\
\hline DRIVER-RRCKI [2] & $\mathrm{d} 5$ & 0.09 & 174 & 293 & $\mathrm{H} 2 / \mathrm{O} 2 / \mathrm{N} 2$ & 1 \\
\hline DRIVER-RRCKI [2] & $\mathrm{d} 6$ & 0.3 & 174 & 293 & $\mathrm{H} 2 / \mathrm{O} 2 / \mathrm{N} 2$ & 1 \\
\hline DRIVER-RRCKI [2] & $\mathrm{d} 7$ & 0.6 & 174 & 293 & $\mathrm{H} 2 / \mathrm{O} 2 / \mathrm{N} 2$ & 1 \\
\hline DRIVER-RRCKI [2] & $\mathrm{d} 8$ & 0.9 & 174 & 293 & $\mathrm{H} 2 / \mathrm{O} 2 / \mathrm{N} 2$ & 1 \\
\hline DRIVER-RRCKI [2] & $\mathrm{e} 1$ & 0.09 & 174 & 293 & $\mathrm{H} 2 / \mathrm{O} 2 / \mathrm{He}$ & 1 \\
\hline DRIVER-RRCKI [2] & $\mathrm{e} 2$ & 0.3 & 174 & 293 & $\mathrm{H} 2 / \mathrm{O} 2 / \mathrm{He}$ & 1 \\
\hline DRIVER-RRCKI [2] & e3 & 0.6 & 174 & 293 & $\mathrm{H} 2 / \mathrm{O} 2 / \mathrm{He}$ & 1 \\
\hline DRIVER-RRCKI [2] & e5 & 0.09 & 174 & 293 & $\mathrm{H} 2 / \mathrm{O} 2 / \mathrm{Ar}$ & 1 \\
\hline DRIVER-RRCKI [2] & e6 & 0.3 & 174 & 293 & $\mathrm{H} 2 / \mathrm{O} 2 / \mathrm{Ar}$ & 1 \\
\hline DRIVER-RRCKI [2] & e7 & 0.6 & 174 & 293 & $\mathrm{H} 2 / \mathrm{O} 2 / \mathrm{Ar}$ & 1 \\
\hline FLAME-SNL[7] & $\mathrm{fl}$ & 0.33 & 1830 & 293 & H2/air & $<1$ \\
\hline FLAME-SNL [7] & $\mathrm{f} 2$ & 0 & 1830 & 293 & H2/air & $<1$ \\
\hline FZK [2] & $\mathrm{g} 1$ & 0.6 & 350 & 293 & H2/air & $<1 ;>1$ \\
\hline FZK [2] & g2 & 0.6 & 350 & 293 & $\mathrm{H} 2 / \mathrm{O} 2 / \mathrm{N} 2$ & 1 \\
\hline FZK [2] & g3 & 0.6 & 350 & 293 & $\mathrm{H} 2 / \mathrm{O} 2 / \mathrm{He}$ & 1 \\
\hline FZK [2] & $\mathrm{g} 4$ & 0.6 & 350 & 293 & $\mathrm{H} 2 / \mathrm{O} 2 / \mathrm{Ar}$ & 1 \\
\hline FZK [2] & g5 & 0.6 & 350 & 293 & $\mathrm{H} 2 / \mathrm{O} 2 / \mathrm{CO} 2$ & 1 \\
\hline FZK [2] & $\mathrm{g} 6$ & 0.6 & 350 & 293 & $\mathrm{H} 2 / \mathrm{air} / \mathrm{CO} 2$ & .5 \\
\hline FZK [2] & g7 & 0.6 & 350 & 293 & $\mathrm{H} 2 / \mathrm{air} / \mathrm{CO} 2$ & 1 \\
\hline FZK [2] & g8 & 0.6 & 350 & 293 & $\mathrm{H} 2 / \mathrm{air} / \mathrm{CO} 2$ & 2 \\
\hline FZK [2] & g9 & 0.6 & 350 & 293 & $\mathrm{H} 2 / \mathrm{air} / \mathrm{CO} 2$ & 4 \\
\hline RUT-RRCKI [5] & $\mathrm{rl}$ & 0.6 & 2250 & 293 & H2/air & $<1$ \\
\hline RUT-RRCKI [5] & $\mathrm{r} 2$ & 0.3 & 2250 & 293 & H2/air & $<1$ \\
\hline RUT-RRCKI [5] & $\mathrm{r} 3$ & 0 & 2250 & 293 & H2/air & $<1$ \\
\hline RUT-RRCKI [6] & $\mathrm{r} 4$ & 0.3 & 2250 & 375 & $\mathrm{H} 2 / \mathrm{air} / \mathrm{H} 2 \mathrm{O}$ & $\leq 1$ \\
\hline HDT-SNL [4] & $\mathrm{s} 1$ & 0.6 & 406 & 383 & H2/air & $>1$ \\
\hline HDT-SNL [4] & s2 & 0.3 & 406 & 383 & $\mathrm{H} 2 /$ air/H2O & $>1$ \\
\hline TORPEDO-RRCKI [2] & t1 & 0.6 & 520 & 293 & H2/air & $<1 ;>1$ \\
\hline TORPEDO-RRCKI [2] & $t 2$ & 0.6 & 520 & 293 & $\mathrm{H} 2 / \mathrm{O} 2 / \mathrm{He}$ & 1 \\
\hline TORPEDO-RRCKI [2] & t3 & 0.3 & 520 & 293 & H2/air & $<1 ;>1$ \\
\hline TORPEDO-RRCKI [2] & t4 & 0.1 & 520 & 293 & H2/air & $<1 ;>1$ \\
\hline
\end{tabular}




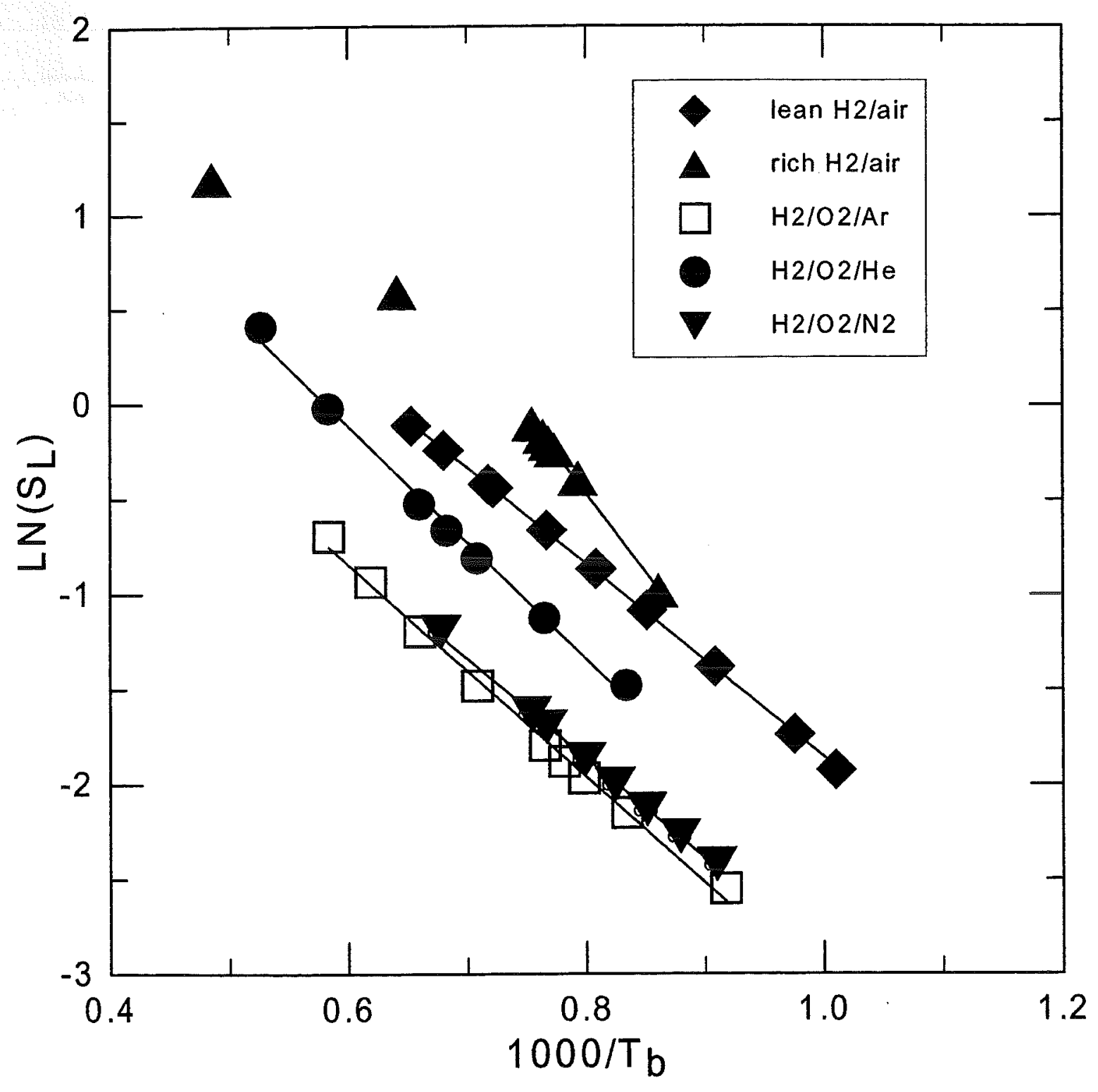

Figure 1. Arrhenius plots of laminar burning velocities $S_{L}$ in $\mathrm{m} / \mathrm{s}$ versus maximum flame temperature $T_{b}$ 


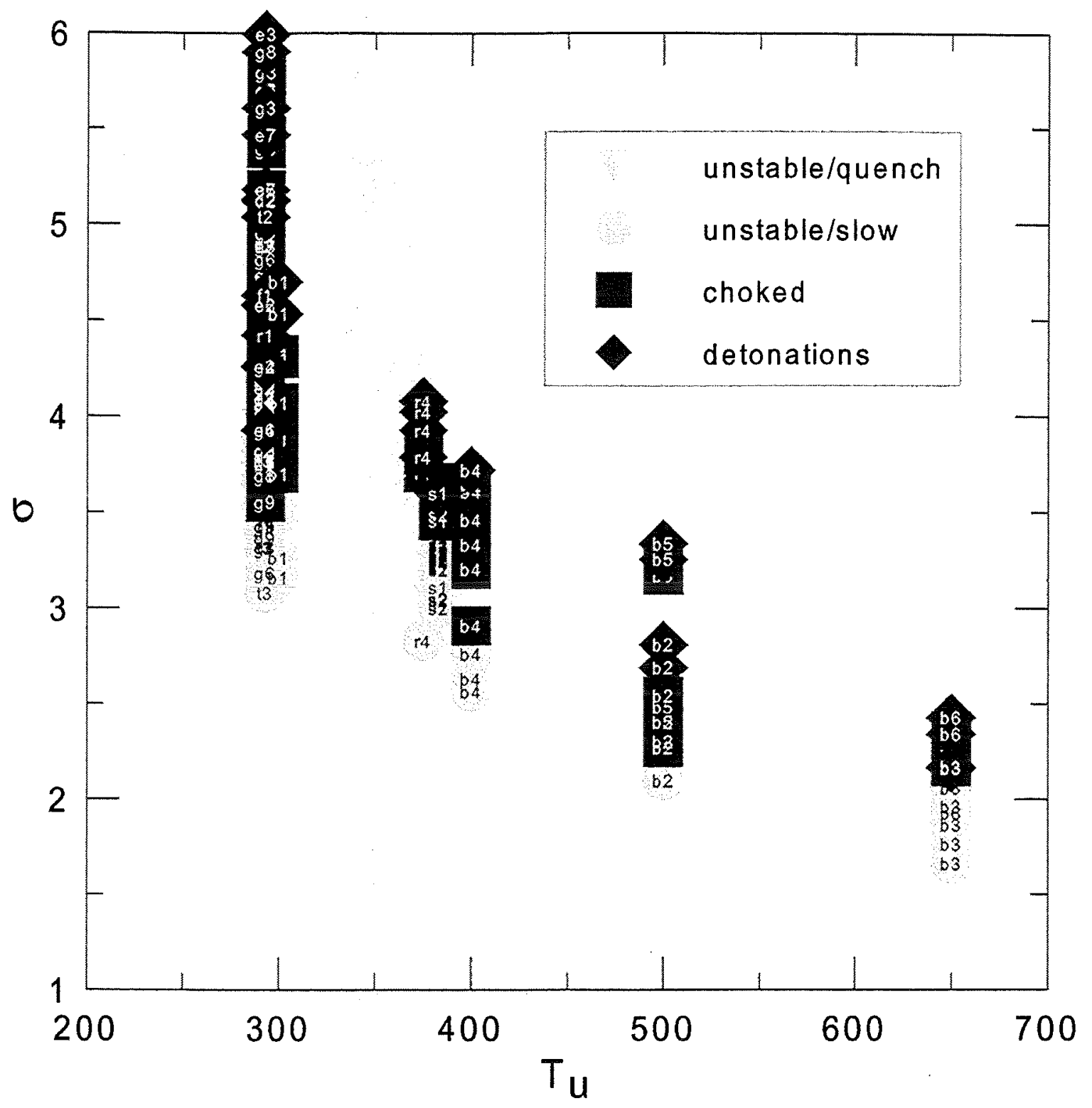

Figure 2. Resulting combustion regime as a function of expansion ratio $\sigma$ and initial temperature $T_{u}$. Black points - fast and gray points - slow combustion regimes. 


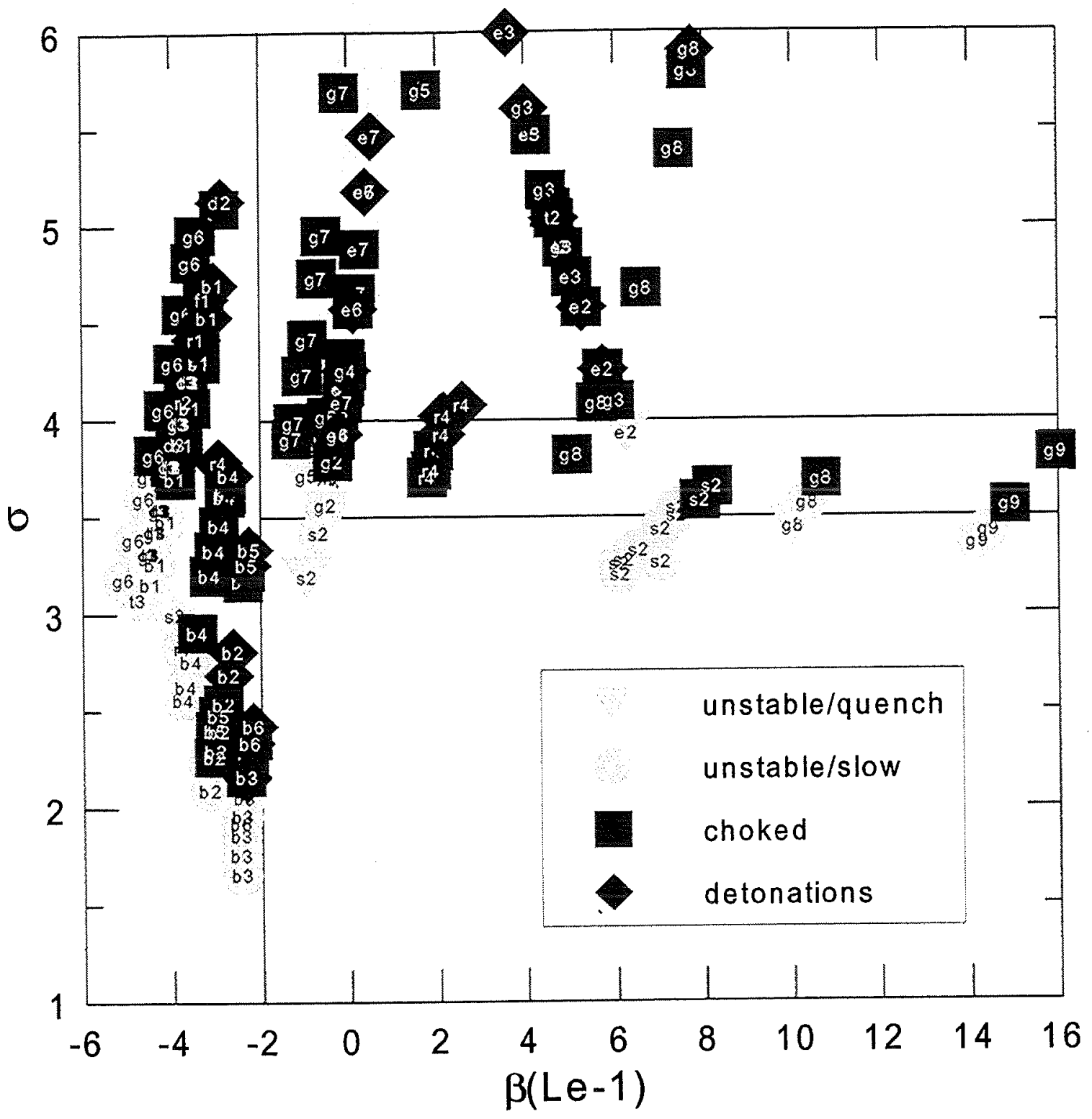

Figure 3. Resulting combustion regime as a function of expansion ratio $\sigma$ and $\beta(L e-1)$. Black points - fast and gray points - slow combustion regimes. 


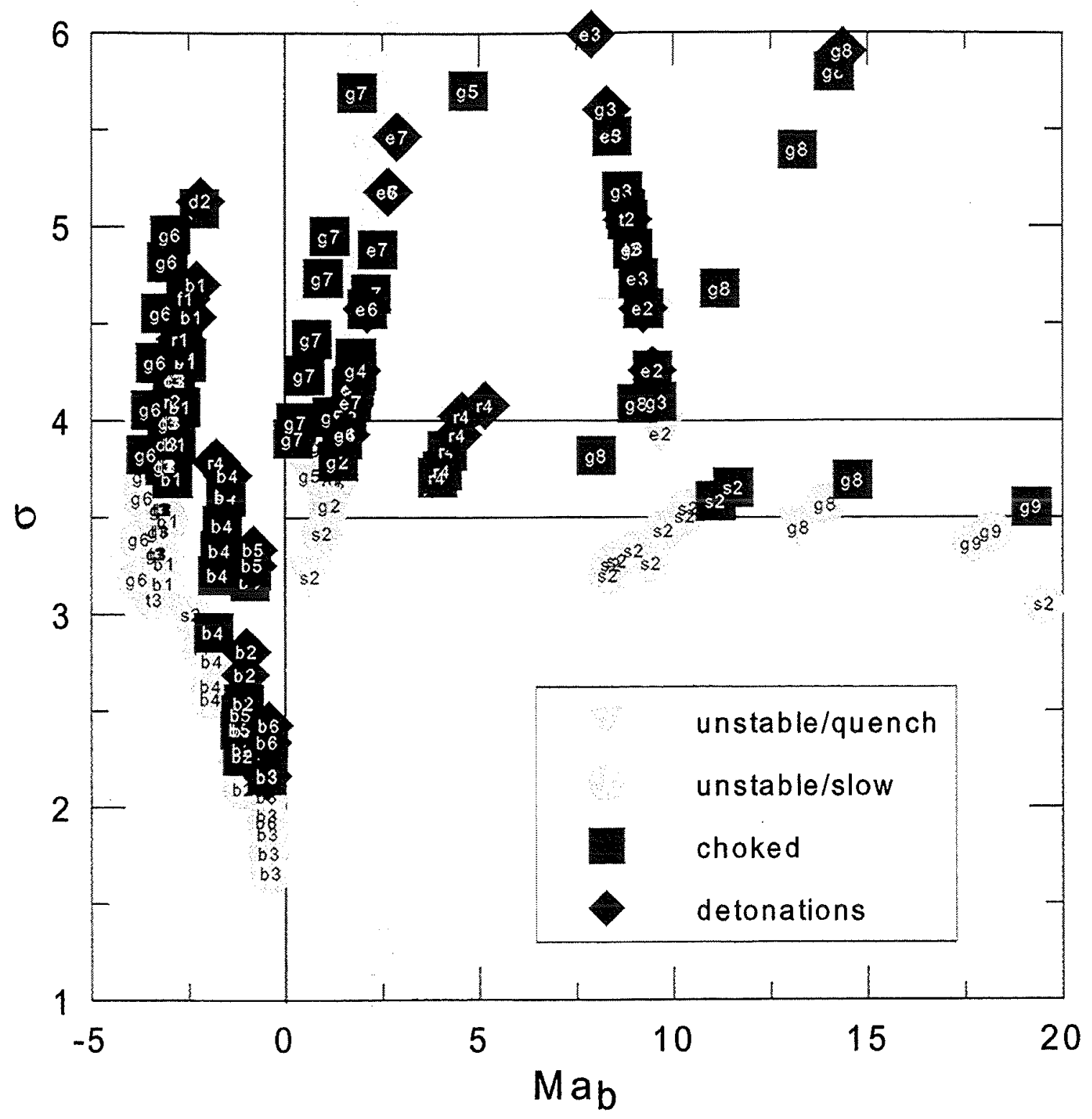

Figure 4. Resulting combustion regime as a function of expansion ratio $\sigma$ and $M a_{b}$. Black points - fast and gray points - slow combustion regimes. 


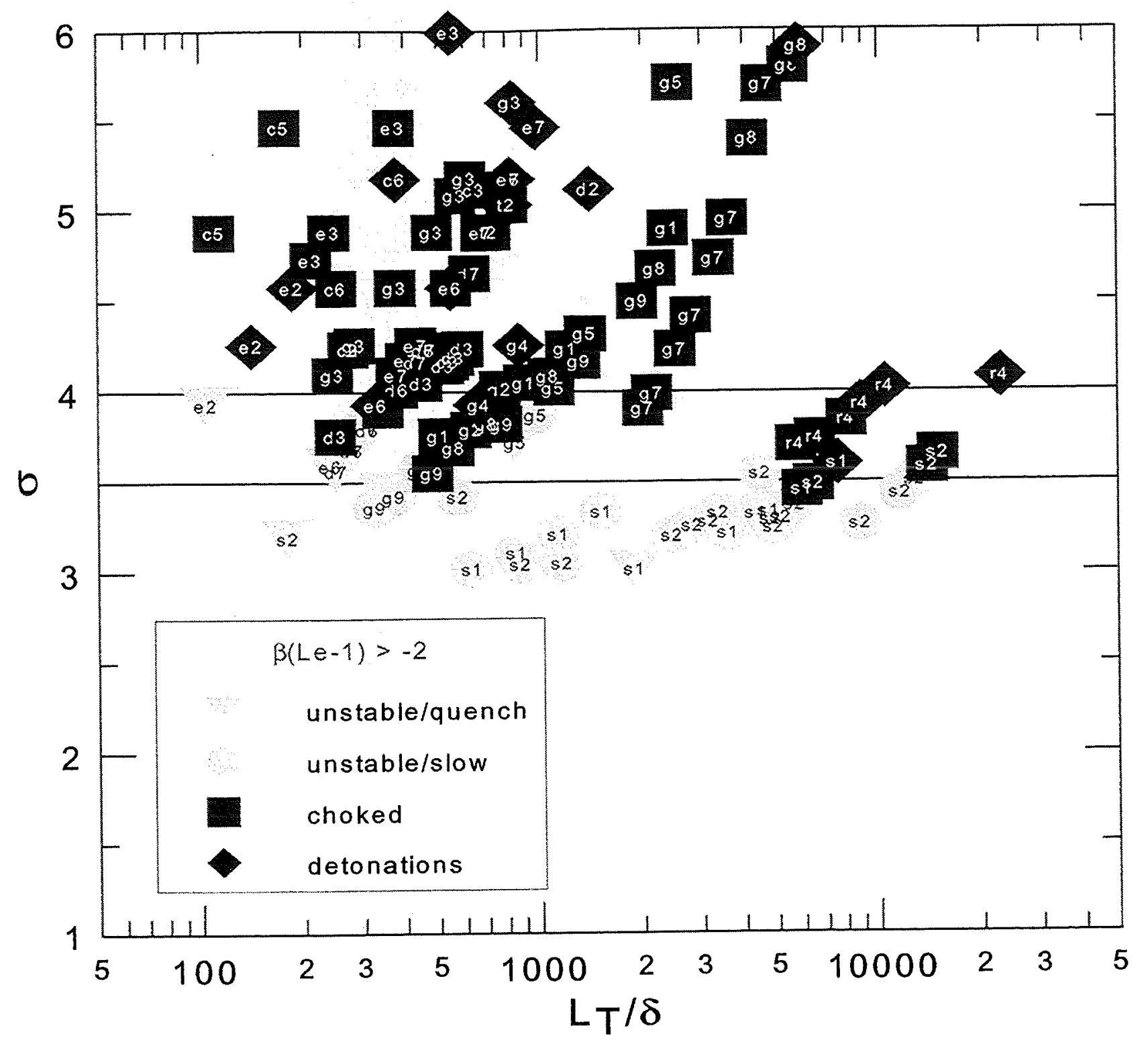

Figure 5. Resulting combustion regime as a function of expansion ratio $\sigma$ and scale ratio $L_{T} / \delta$ for mixtures with $\beta(L e-1)>-2$. Black points - fast and gray points - slow combustion regimes. 


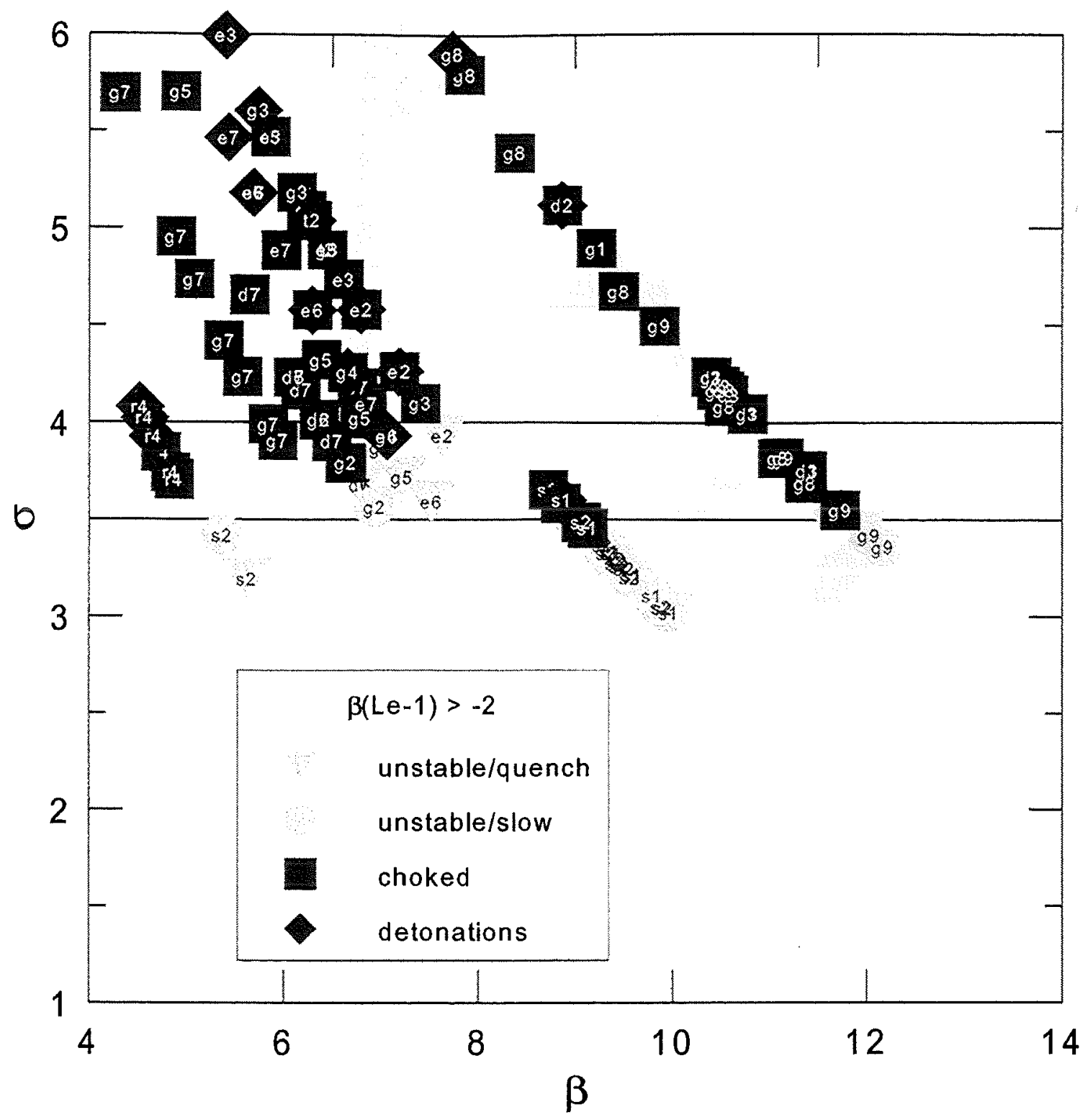

Figure 6. Resulting combustion regime as a function of expansion ratio $\sigma$ and Zeldovich number $\beta$ for mixtures with $\beta(L e-1)>-2$. Black points - fast and gray points - slow combustion regimes. 


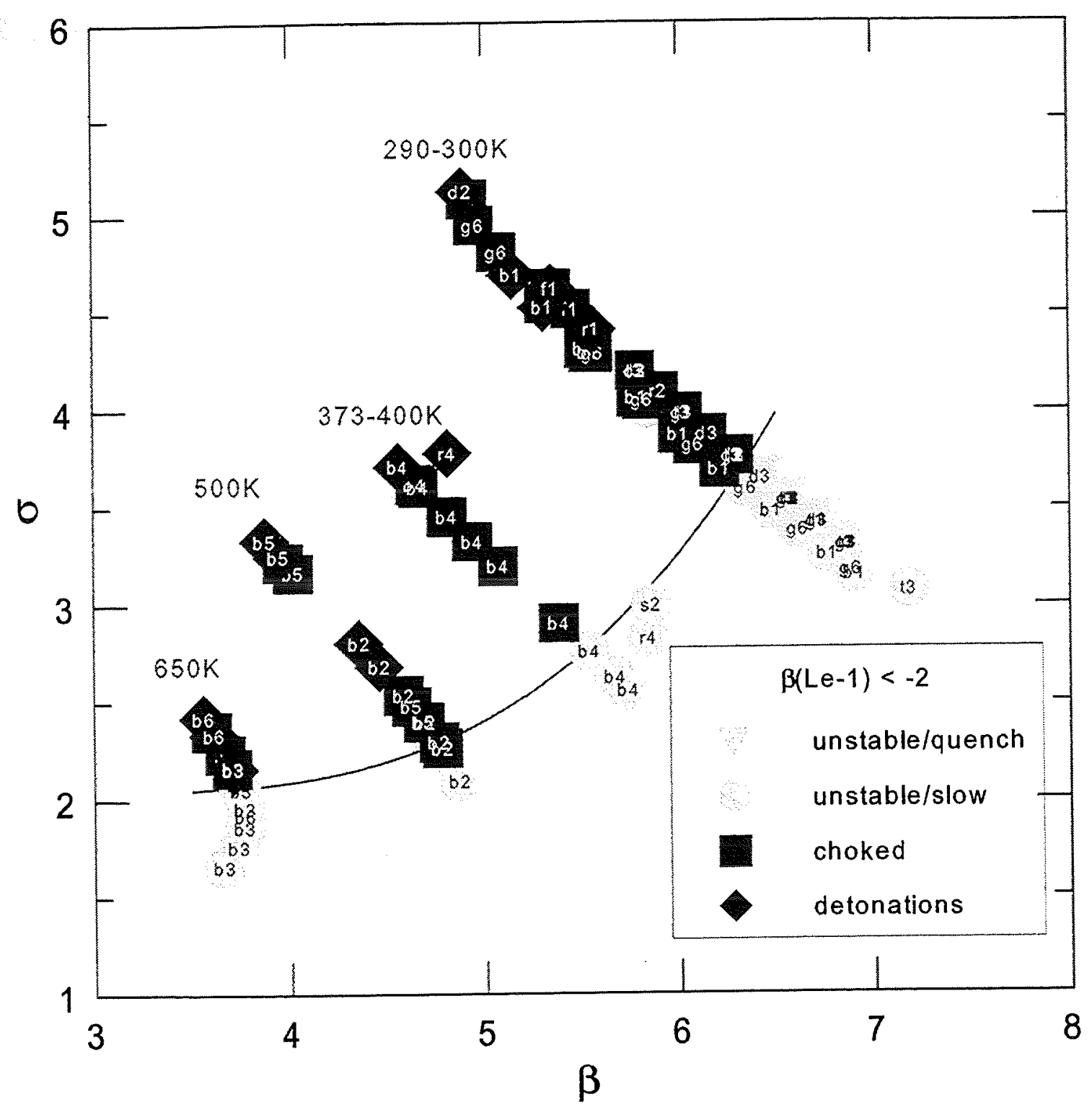

Figure 7. Resulting combustion regime as a function of expansion ratio $\sigma$ and Zeldovich number $\beta$ for mixtures with $\beta(L e-1)<-2$. Black points - fast and gray points - slow combustion regimes. Groups of points are marked with values of initial temperatures for hydrogen-air-steam mixtures. 


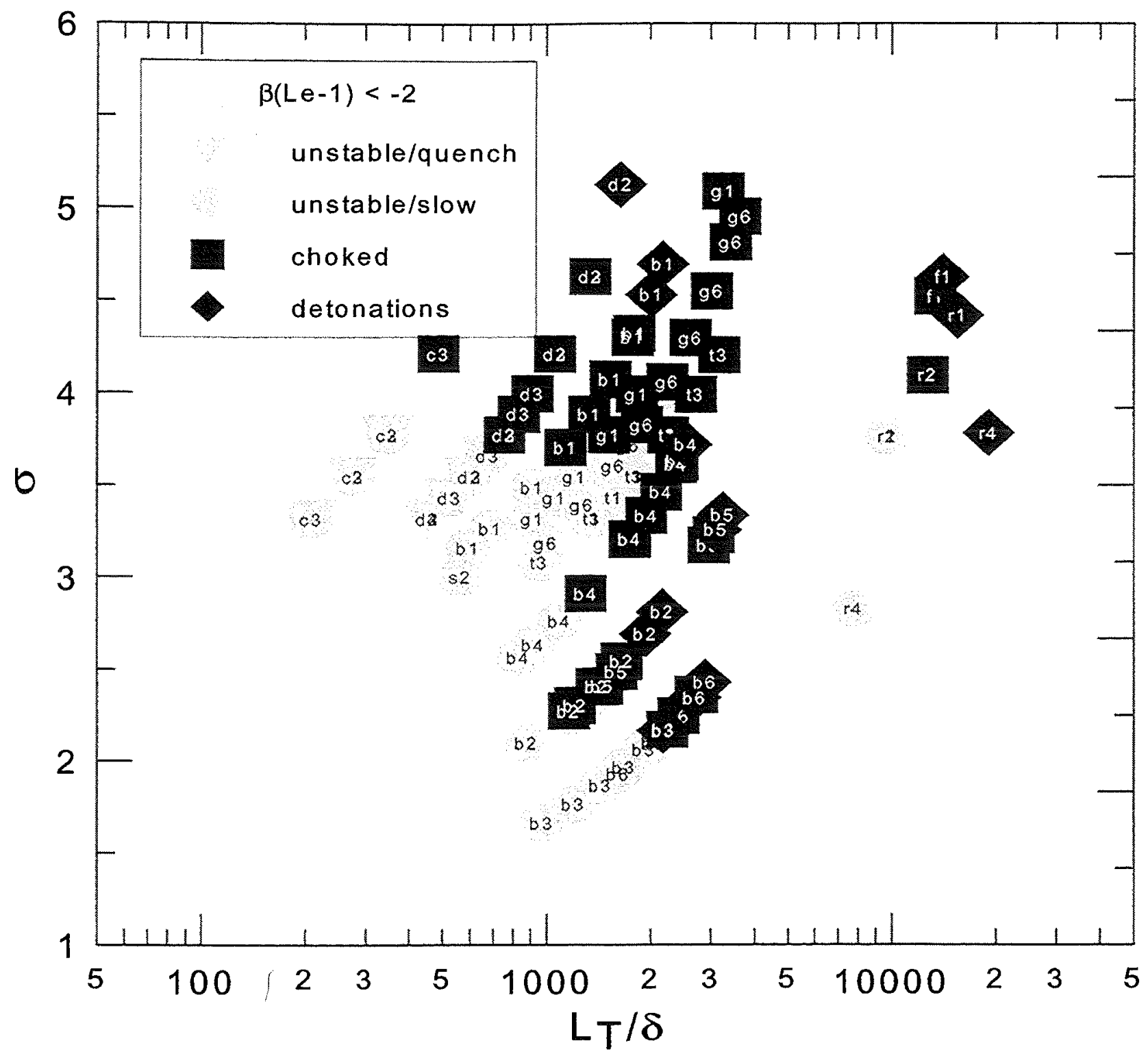

Figure 8. Resulting combustion regime as a function of expansion ratio $\sigma$ and scale ratio $L_{T} / \delta$ for mixtures with $\beta(L e-1)<-2$. Black points - fast and gray points - slow combustion regimes. 


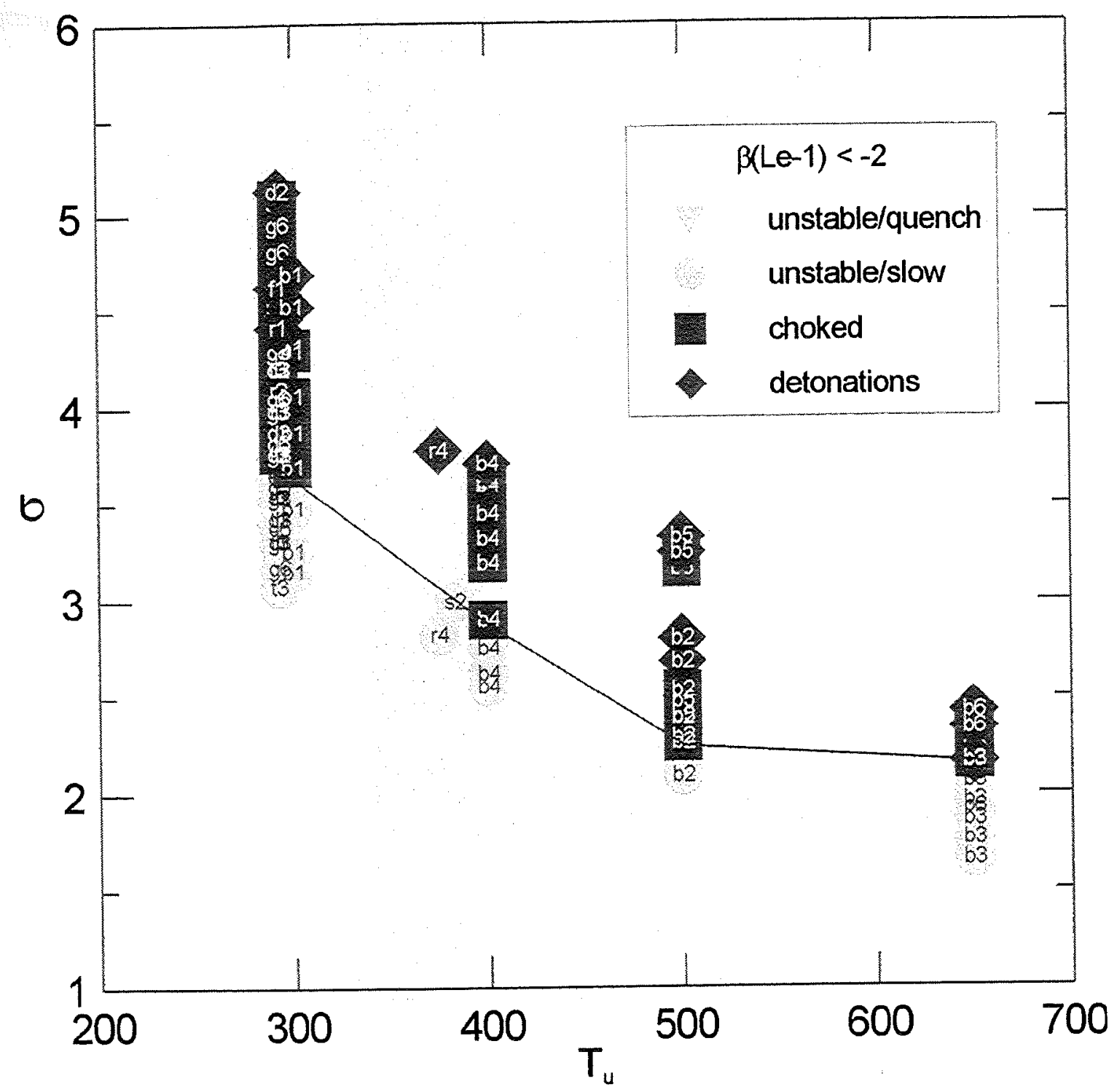

Figure 9. Resulting combustion regime as a function of expansion ratio $\sigma$ and initial temperature $T_{\mathrm{u}}$ for mixtures with $\beta(L e-1)<-2$. Black points - fast and gray points - slow combustion regimes. 


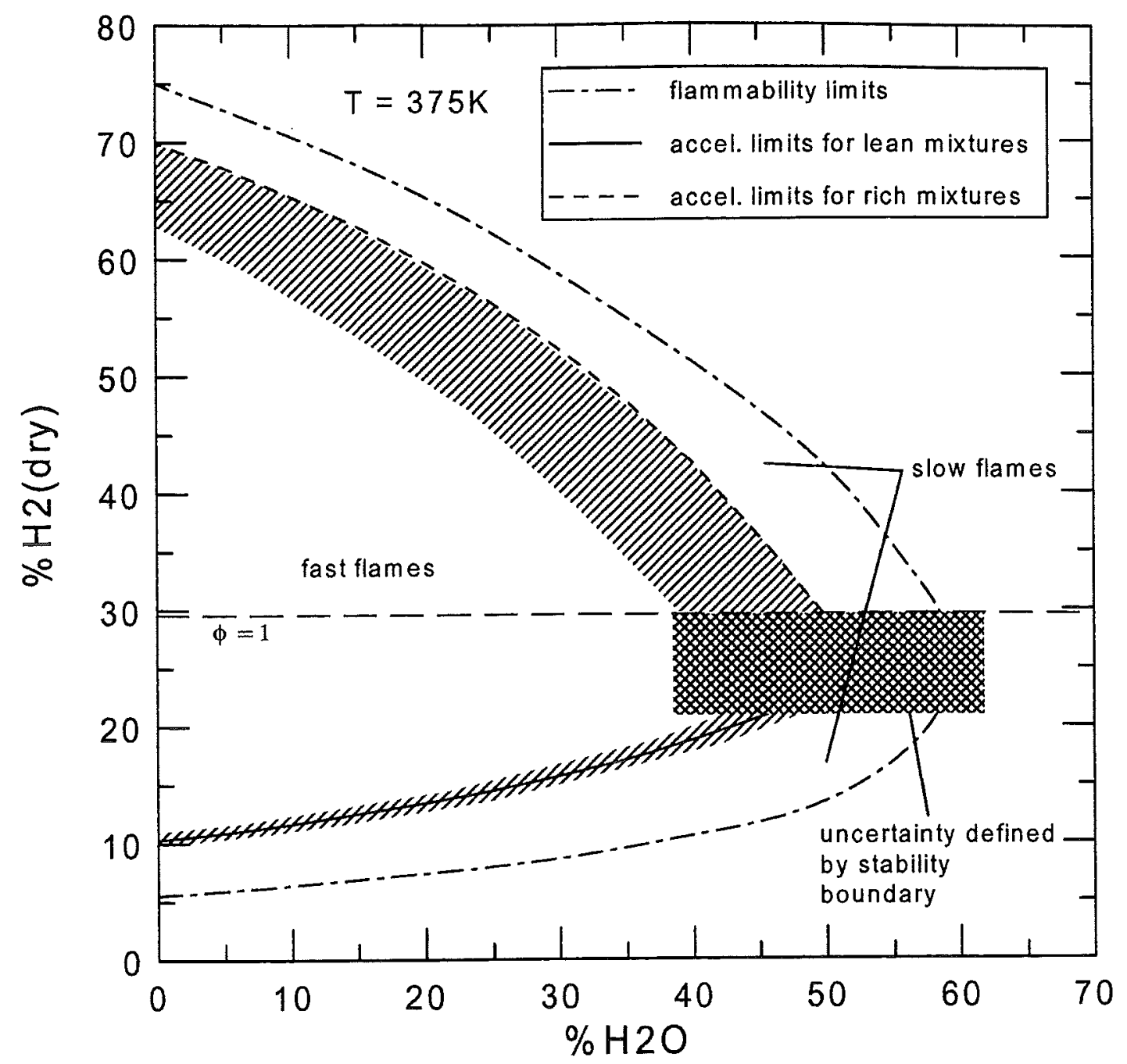

Figure 10. Limits of flame acceleration for hydrogen-air-steam mixtures at $\mathrm{T}=375 \mathrm{~K}$ and $\mathrm{p}=1 \mathrm{~atm}$. Ranges of uncertainties are shown by shadow areas. 